\title{
Altered myocardial gene expression profiling in the ischemic tissues at different time points after cardiac ischemia/ reperfusion in rats
}

\author{
Zhi-Xiao Li, ${ }^{1, *}$, Qiong Lin ${ }^{2, *}$, Zhi-Gang He ${ }^{1}$, Quan Wang ${ }^{1}$, Ying-Le Chen ${ }^{3}$, Mao-Hui \\ Feng $^{4}$, Shun-Yuan $\mathbf{L i}^{3}$ and Hong-Bing Xiang ${ }^{1}$ \\ ${ }^{1}$ Department of Anesthesiology and Pain Medicine, Tongji Hospital, Tongji Medical College, Huazhong University of Science \\ and Technology, Wuhan 430030, China \\ ${ }^{2}$ Department of Anesthesiology, Guangdong Provincial Hospital of Chinese Medicine, Guangzhou 510120, China \\ ${ }^{3}$ Department of Anesthesiology, The First Affiliated Quanzhou Hospital of Fujian Medical University, Quanzhou 362000, China \\ ${ }^{4}$ Department of Oncology, Wuhan Peritoneal Cancer Clinical Medical Research Center, Zhongnan Hospital of Wuhan University, \\ Hubei Key Laboratory of Tumor Biological Behaviors and Hubei Cancer Clinical Study Center, Wuhan 430071, China \\ *These authors contributed equally to this work \\ Correspondence to: Shun-Yuan Li, email: cylfj@126.com \\ Hong-Bing Xiang, email: xhbtj2004@163.com
}

Keywords: cardiac ischemia/reperfusion injury; differentially expressed genes; IncRNAs; real-time quantitative PCR

Received: October 07, $2017 \quad$ Accepted: November 13, $2017 \quad$ Published: January 03, 2018

Copyright: Li et al. This is an open-access article distributed under the terms of the Creative Commons Attribution License 3.0 (CC BY 3.0), which permits unrestricted use, distribution, and reproduction in any medium, provided the original author and source are credited.

\section{ABSTRACT}

We used Agilent Gene Expression microarray to analyze differential gene and IncRNA expression patterns in the myocardial ischemia regions during ischemia/ reperfusion ( $I / R)$-induced cardiac injury in rats. Male SD rats were assigned into control group, 2 h group (30 min ischemia followed by $2 \mathrm{~h}$ reperfusion), $0.5 \mathrm{~h}$ (30 min ischemia followed by $0.5 \mathrm{~h}$ reperfusion) group. We observed that of 18090 IncRNAs, an average of 233 IncRNAs was up-regulated in ischemic tissues of $\mathbf{2} \mathbf{h}$ group, compared with those in control group, while an average of 6115 IncRNAs was down-regulated (with a $>2.0$ fold-change and $p<0.05$ ). Further, a total of 3135 mRNAs were differentially expressed between control group and $2 \mathrm{~h}$ group, in which 542 mRNAs were up-regulated and 2593 mRNAs were down-regulated. Some differentially expressed genes were validated by qRT-PCR analyses of select IncRNAs in different time points after cardiac $I / R$ injury. We unveiled that the expressions of IncRNA XR_345533.2, NONRATT025386, NONRATT024318, XR_599241.1, and NONRATT025509 were significantly up-regulated in $2 \mathrm{~h}$ group compared with control group and $0.5 \mathrm{~h}$ group, whereas the expression of IncRNA NR_130708.1 was downregulated after cardiac I/R injury and had no statistically different between $0.5 \mathrm{~h}$ group and $2 \mathrm{~h}$ group. Otherwise, the expressions of IncRNA NONRATT028627, NONRATT021959, XR_590005.1 and NONRATT023191 were significantly up-regulated in $2 \mathrm{~h}$ group compared with $0.5 \mathrm{~h}$ group. These findings provide evidence for differential expression patterns of $m$ RNAs and IncRNAs in the ischemic tissues after cardiac $I / R$ injury in rats.

\section{INTRODUCTION}

Cardiomyocyte death due to ischemia/reperfusion (I/R) injury is well-known to increase morbidity, mortality and medical cost in patients with ischemic heart disease [1-4]. Treatment for this myocardial ischemia-reperfusion disorder and cardiomyocyte death has had limited success. The pathological process leading to cardiomyocyte death is very complicated and our understanding of the mechanisms that underlie the induction of cardiomyocyte death is incomplete [5, 6]. IRI-induced cardiomyocyte death is thought to be triggered by abnormal changes 
in gene transcription and translation [7-10]. Data from an increasing number of studies have indicated that IRI dysregulates expression of mRNA and protein for the receptors, enzymes and ion channels in the heart, a phenomenon that may contribute to the induction of cardiomyocyte death [11-14]. However, the molecular mechanisms that underlie this regulation for myocardial ischemia-reperfusion disorder are still unknown.

Recently, long non-coding RNAs (lncRNAs) have become an increased research focus that plays critical roles in many biological processes [15-20]. Recent studies suggest that lncRNAs are often accompanied by important regulatory functions in the heart [21-23]. However, the lncRNAs study for heart is still in its infancy, and the signature and roles of differential gene and lncRNAs expression in the I/R-induced cardiomyocyte death have received relatively little attention. Otherwise, the details regarding differential gene and lncRNAs expression involvement in ischemia myocardial tissues at different time points are unknown. In this study, we tested the differential gene and lncRNAs expression profiles in the myocardial tissues following myocardial ischemiareperfusion injury in rat and investigated the possible roles of these differential gene and lncRNAs at different stages of ischemia-reperfusion.

\section{RESULTS}

\section{Aberrant IncRNA expression in the ischemic tissues $2 \mathrm{~h}$ after reperfusion}

In order to select out possible targets of lncRNAs between model and control group, up to 18090 coding transcripts were detected in the ischemic tissues of the heart at $2 \mathrm{~h}$ after reperfusion. An average of $233 \mathrm{lncRNAs}$ was up-regulated in ischemic tissues, compared with those in control group, while an average of $6115 \operatorname{lncRNAs}$ was down-regulated (with a $>2.0$ fold-change and $p<0.05$ ). The distributions of the $\log 2$ ratios of $\operatorname{lncRNAs}$ between model and control samples were nearly identical. Figure 1 showed the heat maps of the expression ratios ( $\log 2$ scale) of lncRNAs in the ischemic tissues. The top 20 up-regulated and down-regulated lncRNAs are listed in Tables 1 and 2 .

\section{Aberrant mRNA expression in the ischemic tissues after reperfusion}

To identify altered genes that may contribute to myocardial I/R injury, we conducted mRNA profiling experiment on the ischemic tissues. The mRNA expressions of the ischemic tissues in the rats were examined using Agilent Rat Gene Expression microarrays that include 27,006 probe sets. The gene expression profiles in I/R group were compared with the corresponding data of control group. We identified that a total of 3135 probe sets were differentially expressed in two groups (with a $>2.0$ fold-change and $p<0.05$ ), in which 542 probe sets were up-regulated and 2593 probe sets were down-regulated. Figure 2 showed the heat maps of the expression ratios ( $\log 2$ scale) of mRNAs. The top 20 up-regulated and down-regulated mRNAs from the myocardial ischemic regions are listed in Tables 3 and 4.The maximal and minimal fold change was 25.97 and 2.0 , respectively.

\section{Gene ontology annotation for differential expression genes}

The differentially expressed genes identified by Agilent Gene Expression microarrays were analyzed by Gene Ontology (GO) annotation. Figure 3 showed the significant enriched GO Terms (Top 30) including three biological functional groups (biological process, cellular component and molecular function). We found that the differentially expressed genes from the myocardial ischemic regions were primarily involved in sensory perception, neurological process, G-protein coupled receptor signaling pathway (Figure 3 ).

\section{KEGG Pathway enrichment analysis}

Kyoto Encyclopedia of Genes and Genomes (KEGG) pathway enrichment analyses of the differentially expressed genes were performed to identify the molecular changes of the myocardial ischemic regions. Figure 4 showed the significant enriched pathway Terms (Top 30) primarily involved in KEGG pathway including olfactory transduction, neuroactive ligand-receptor interaction, cytokine-cytokine receptor interaction, retinol metabolism, and steriod hormone biosynthesis. Figure 5 showed the differential expression genes were analyzed with GO background significant enrichment. The top five enriched GO biological processes included single-organism process, metabolic process, response to stimulus, biological regulation, and cellular aggregation. The most enriched GO cellular components included extracellular region part, macromolecular complex, membrane-enclosed lumen. The enriched GO molecular functions were catalytic activity, transporter activity, and molecular transducer activity.

\section{Real-time quantitative PCR (RT-qPCR) validation of IncRNAs expression in the myocardial tissues $2 \mathrm{~h}$ after cardiac $\mathrm{I} / \mathrm{R}$ injury}

To validate the reliability of the microarray results in rats, we analyzed these differentially expressed (DE) lncRNAs, including 5 up-regulated lncRNA and 5 downregulated lncRNA by RT-qPCR. The ischemic tissues were collected from control group and I/R group ( $2 \mathrm{~h}$ after reperfusion). Five up-regulated lncRNAs, including XR_345533.2, NONRATT025386, NONRATT024318, 
XR_599241.1, and NONRATT025509 were significantly increased in I/R group compared with control group, whereas one down-regulated IncRNA, NR_130708.1 was significantly decreased (Figure 6). RT-qPCR results of four lncRNA, including NONRATT028627, NONRATT021959, XR_590005.1 and NONRATT023191 were not consistent with data from microarray.

The expression of 10 IncRNA was analyzed in the cardiac tissues at different time points $(0.5 \mathrm{~h} / 2 \mathrm{~h})$ after cardiac $\mathbf{I} / \mathbf{R}$ injury

It is well-known that gene expressions are varied in different time points. We collected myocardial tissue samples $0.5 \mathrm{~h}$ vs $2 \mathrm{~h}$ after cardiac I/R injury for RT-qPCR validation. Our results indicated that the expressions of lncRNA XR_345533.2, NONRATT025386, NONRATT024318, X̄̄_599241.1, and NONRATT025509 were significantly up-regulated in $2 \mathrm{~h}$ group compared with $0.5 \mathrm{~h}$ group, whereas the expression of IncRNA NR_130708.1 had no statistically different between $0.5 \mathrm{~h}$ group and 2h group (Figure 6, Figure 7 and Figure 8). Otherwise, the expressions of lncRNA NONRATT028627, NONRATT021959, XR_590005.1 and NONRATT023191 were significantly up-regulated in $2 \mathrm{~h}$ group compared with $0.5 \mathrm{~h}$ group.

\section{The expression of 6 IncRNA was analyzed in the cardiac tissues $0.5 \mathrm{~h}$ after cardiac $\mathrm{I} / \mathrm{R}$ injury}

Our results indicated that the expression of lncRNA NONRATT025386 was significantly up-regulated in

\section{A}

Log-Log Scatter Plot
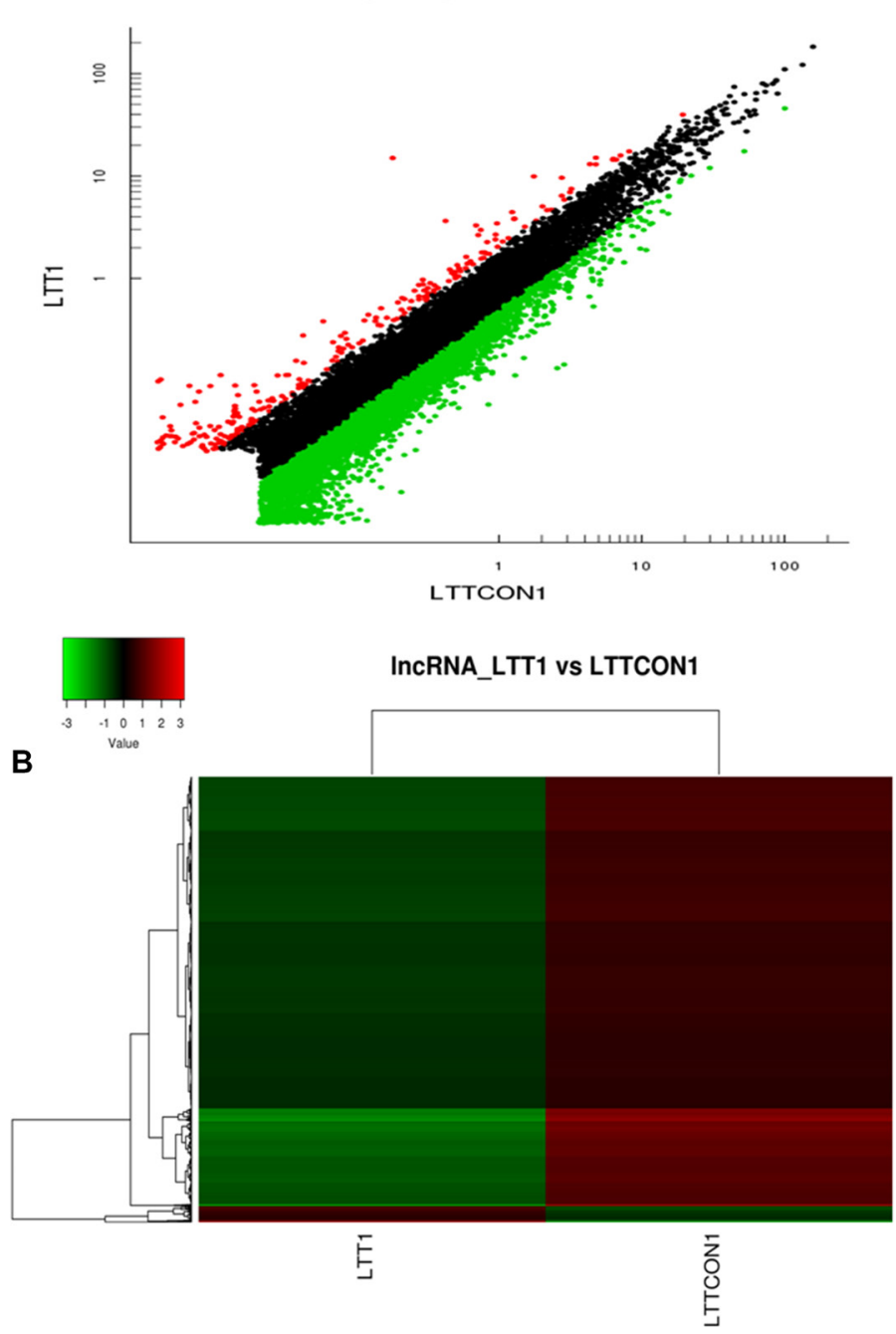

Figure 1: Differential expression IncRNA in the myocardial tissue from the cardiac I/R model. (A) Scatter plot for comparing global lncRNA expression profiles in myocardial tissue between the cardiac I/R and control rat. Red color is indicative of upregulated and blue color of down-regulated genes. Black color of is indicative of not statistical significant difference when it do not pass the cutoff values of 1 and -1 in $\log _{2}$ scale and $p<0.05$. (B) Heat map showing hierarchical clustering of lncRNA whose expression changes were more than twofold. In clustering analysis, up-and down-regulated genes are colored in red and green, respectively. LTT1 stands for Model group; LTTCON1 stands for control group. 
$0.5 \mathrm{~h}$ group compared with control group, whereas the expressions of lncRNA NR_130708.1, NONRATT028627, NONRATT021959, XR_590005.1 and NONRATT023191 were significantly down-regulated in $0.5 \mathrm{~h}$ group compared with control group (Figure 6 and Figure 7).

\section{DISCUSSION}

Cardiomyocyte death due to ischemia/reperfusion injury (IRI) is a great clinical problem. Despite multiple therapeutic strategies, the medical community still faces a challenge to treat cardiac ischemia/reperfusion injury in a complete and definitive way, since the pathogenesis of this ischemia/reperfusion state is very complex. It is essential to discover impactful therapeutic targets by elucidating molecular mechanisms of cardiomyocyte death. Our present work demonstrated many differentially expressed genes, pathways and biological processes in the cardiac ischemic tissues after cardiac I/R injury. By Agilent Rat Gene Expression microarrays, we identified 27,006 mRNAs in the cardiac ischemic tissues from two groups, of which 542 up-regulated and 2593 downregulated mRNAs (with a $>2.0$ fold-change and $p<0.05$ ) were identified in response to cardiac ischemia. Similarly,
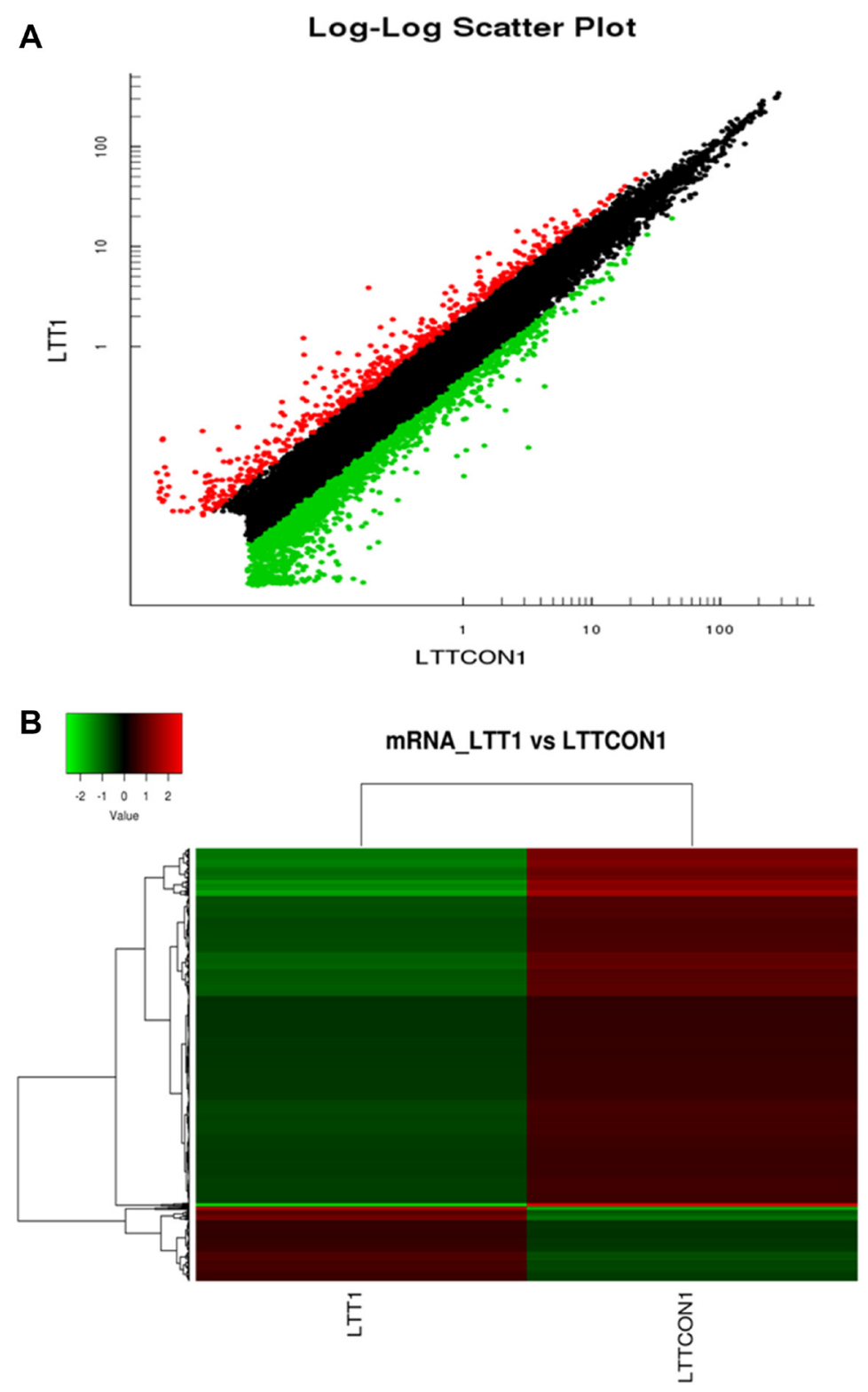

Figure 2: Differential expression genes (mRNA) in the myocardial tissues from the cardiac I/R model. (A) Scatter plot for comparing global mRNA genes expression profiles in myocardial tissue between the cardiac I/R and control rat. Red color is indicative of up-regulated and blue color of down-regulated genes. Black color of is indicative of not statistical significant difference when it do not pass the cutoff values of 1 and -1 in $\log _{2}$ scale and FDR (corrected $p$-value) $<0.05$. (B) Heat map showing hierarchical clustering of mRNA whose expression changes were more than twofold. In clustering analysis, up-and down-regulated genes are colored in red and green, respectively. LTT1 stands for Model group; LTTCON1 stands for control group. 


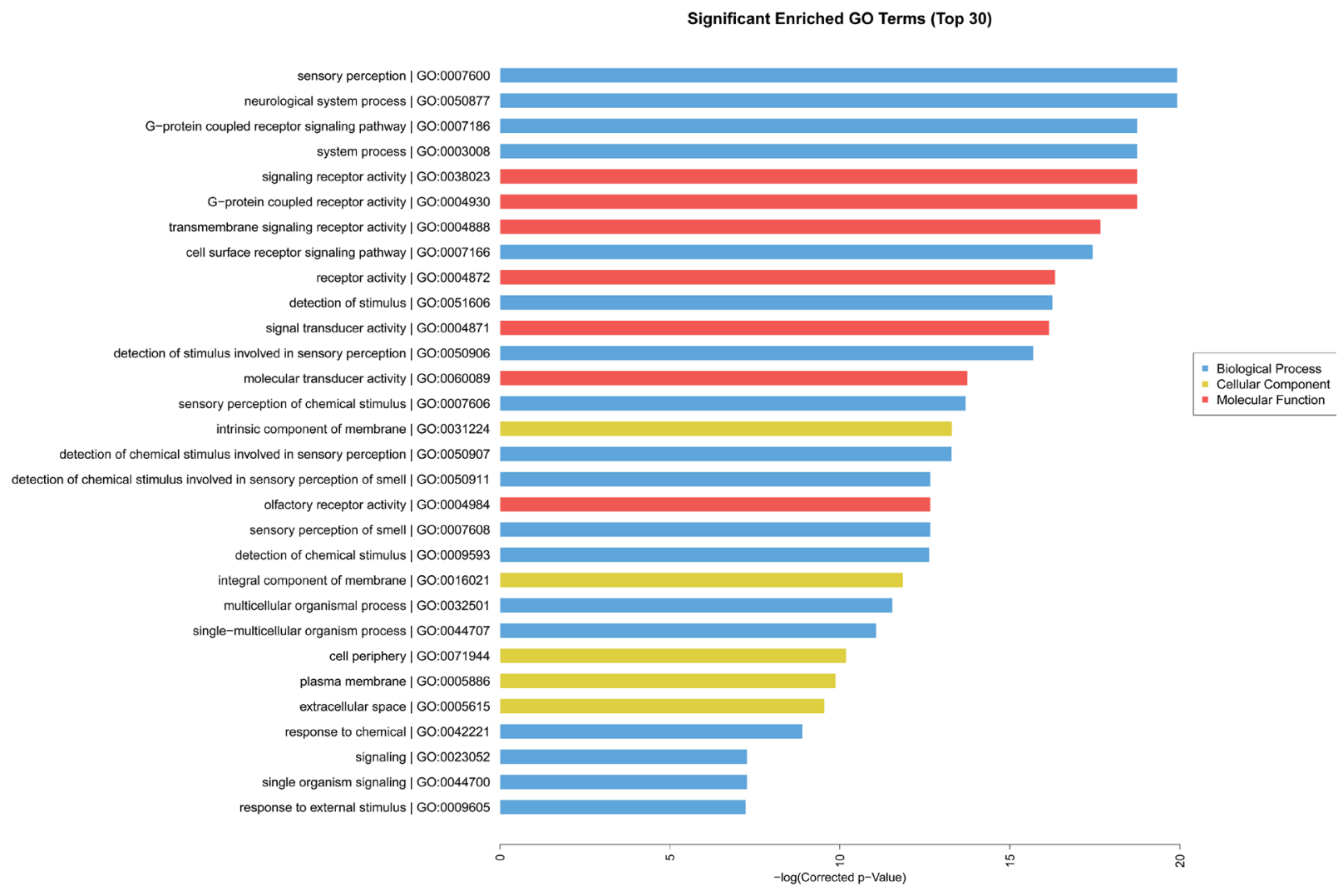

Figure 3: The significant enriched GO Terms (Top 30) were analyzed by Gene Ontology (GO) annotation. Blue bar represents biological process classification; Yellow bar represents cellular component; and Red bar represents molecular function.

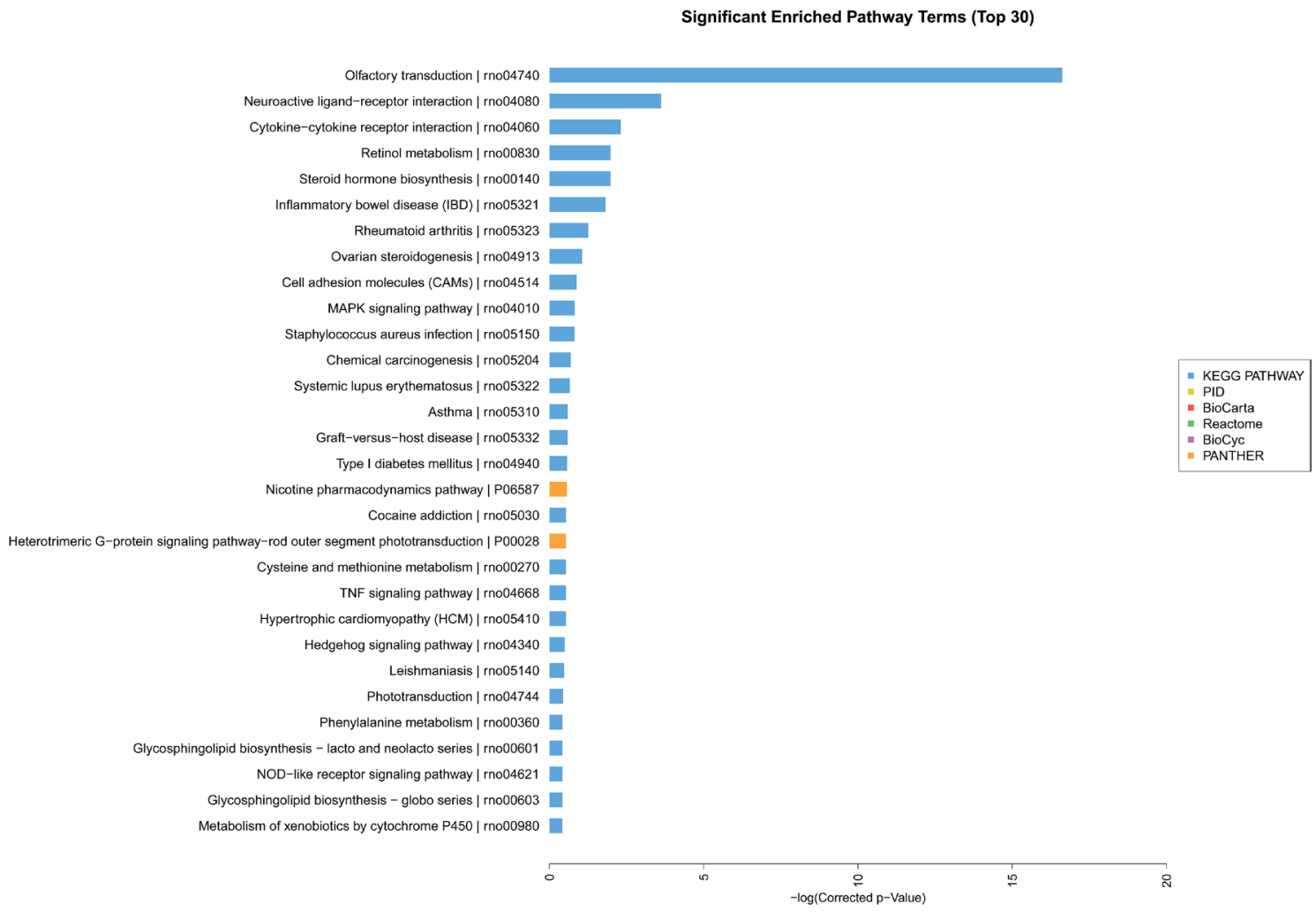

Figure 4: The significant enriched pathway Terms (Top 30) were analyzed by Gene Ontology (GO) annotation. Blue bar represents KEGG pathway and Yellow bar represents Panther. 
Table 1: The detail information of the top 20 up-regulated IncRNAs in the ischemic region at $2 \mathrm{~h}$ after reperfusion

\begin{tabular}{lccc}
\hline Lnc RNAs (seqname) & fold change (R/N) & RNA length & Chromosome \\
\hline NONRATT025386 & 214.8505 & 563 & 6 \\
NONRATT016113 & 60.64338 & 900 & 2 \\
NONRATT018298 & 44.94348 & 520 & 3 \\
NONRATT018300 & 44.80856 & 1134 & 3 \\
NONRATT020994 & 41.33676 & 206 & 4 \\
NONRATT004402 & 40.78394 & 546 & 10 \\
NONRATT028525 & 31.02353 & 469 & 8 \\
NONRATT001626 & 27.2879 & 607 & 1 \\
gi|672028135|ref|XR_594134.1| & 20.66773 & 1408 & 14 \\
gi|672026098|ref|XR_602081.1| & 20.60648 & 887 & 11 \\
NONRATT020441 & 19.0346 & 485 & 4 \\
NONRATT011161 & 18.57801 & 434 & 15 \\
NONRATT013793 & 16.56359 & 2141 & 18 \\
gi|672078992|ref|XR_360168.2| & 15.72723 & 1417 & 15 \\
NONRATT015360 & 15.30411 & 301 & 2 \\
NONRATT013401 & 15.06407 & 673 & 18 \\
NONRATT004403 & 14.84706 & 646 & 10 \\
NONRATT016114 & 13.83695 & 436 & 2 \\
gi|672062648|ref|XR_356473.2| & 13.4567 & 413 & 8 \\
NONRATT027930 & 13.28639 & 585 & 8
\end{tabular}

Values are fold changes (FC) in the reperfusion groups (reperfusion $2 \mathrm{~h}$ ) over the control group (N $>2.0$-fold; $p<0.05$ by analysis of variance)

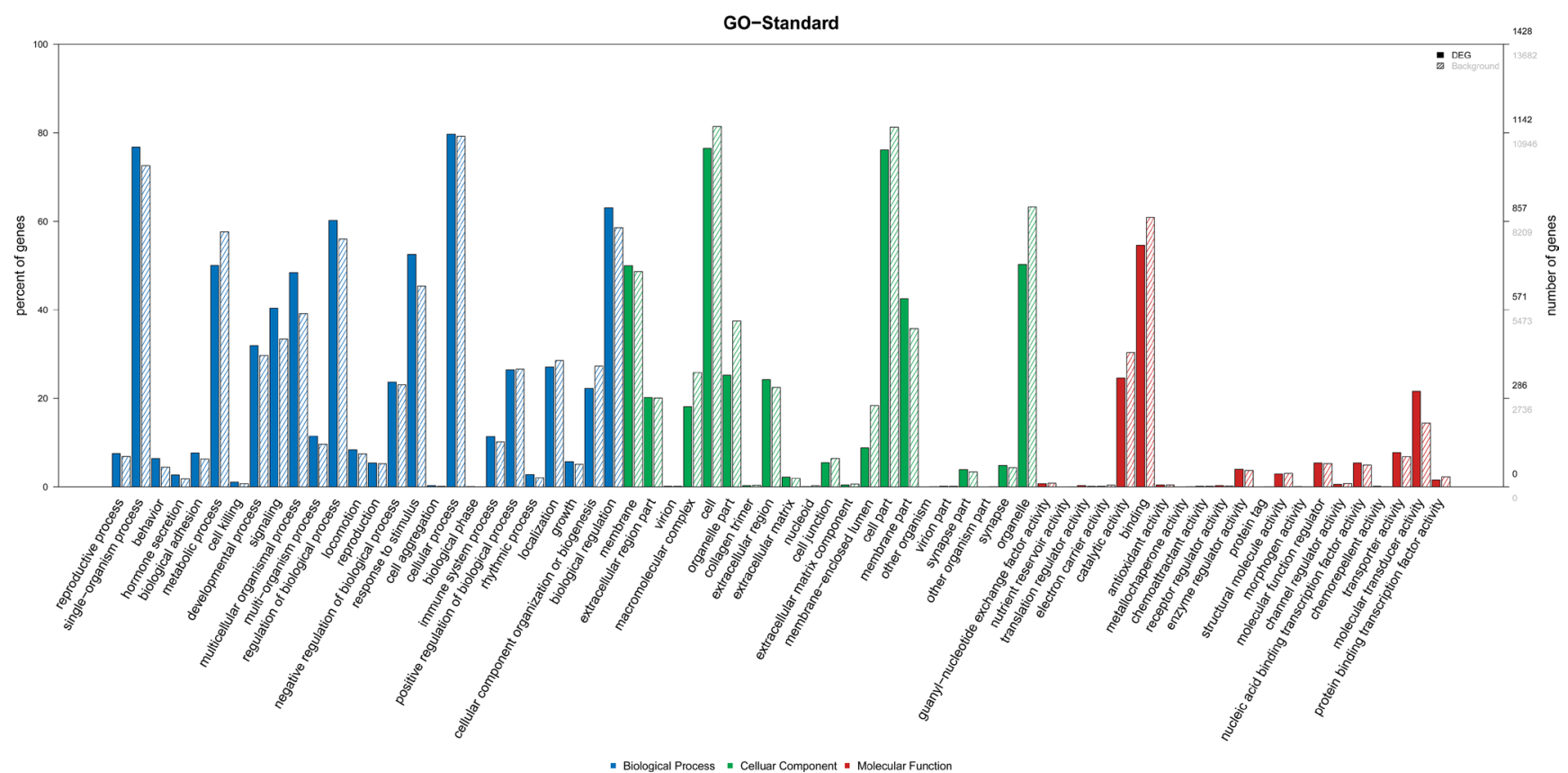

Figure 5: The differential expression genes were analyzed with GO background significant enrichment. Blue bar represents biological process classification; Blue bar represents cellular component; and Red bar represents molecular function. Solid bar represents target genes set, and slash bar represents background genes set. 
18090 lncRNAs of which, 233 up-regulated and 6115 down-regulated lncRNAs were identified upon cardiac ischemia. From this list, we confirmed and verified few differentially expressed lncRNAs by RT-qPCR analyses.

Previous studies have suggested that the altered genes in the myocardial ischemic regions are involved in the regulation of cardiac function and have a protective role in I/R-induced cardiocyte apoptosis [24-27]. Yang et al demonstrated that microRNA-21 had an anti-apoptotic role in I/R-induced myocardial damage via the PTEN/ Akt-dependent mechanism, suggesting that miR-21 may be a promising agent for the treatment of $\mathrm{I} / \mathrm{R}$-induced myocardial injury [27]. Wu et al showed that hypoxia/ reoxygenation significantly increased the release of lactate dehydrogenase, levels of malondialdehyde, and cardiomyocyte apoptosis, but these effects were attenuated by an miR-613 mimic, and programmed cell death 10 (PDCD10) was identified as a target gene of miR-613, suggesting that miR-613 inhibits I/R-induced cardiomyocyte apoptosis by targeting PDCD10 [28]. Díaz et al indicated that administration of urocortin- 1 and urocortin-2 at the beginning of reperfusion significantly restored cardiac function, and intravenous infusion of urocortin-2 in rat model of I/R mimicked the effect of urocortin-1 on miR-324-3p and miR-139-3p, suggesting that a role of urocortin in myocardial protection may be
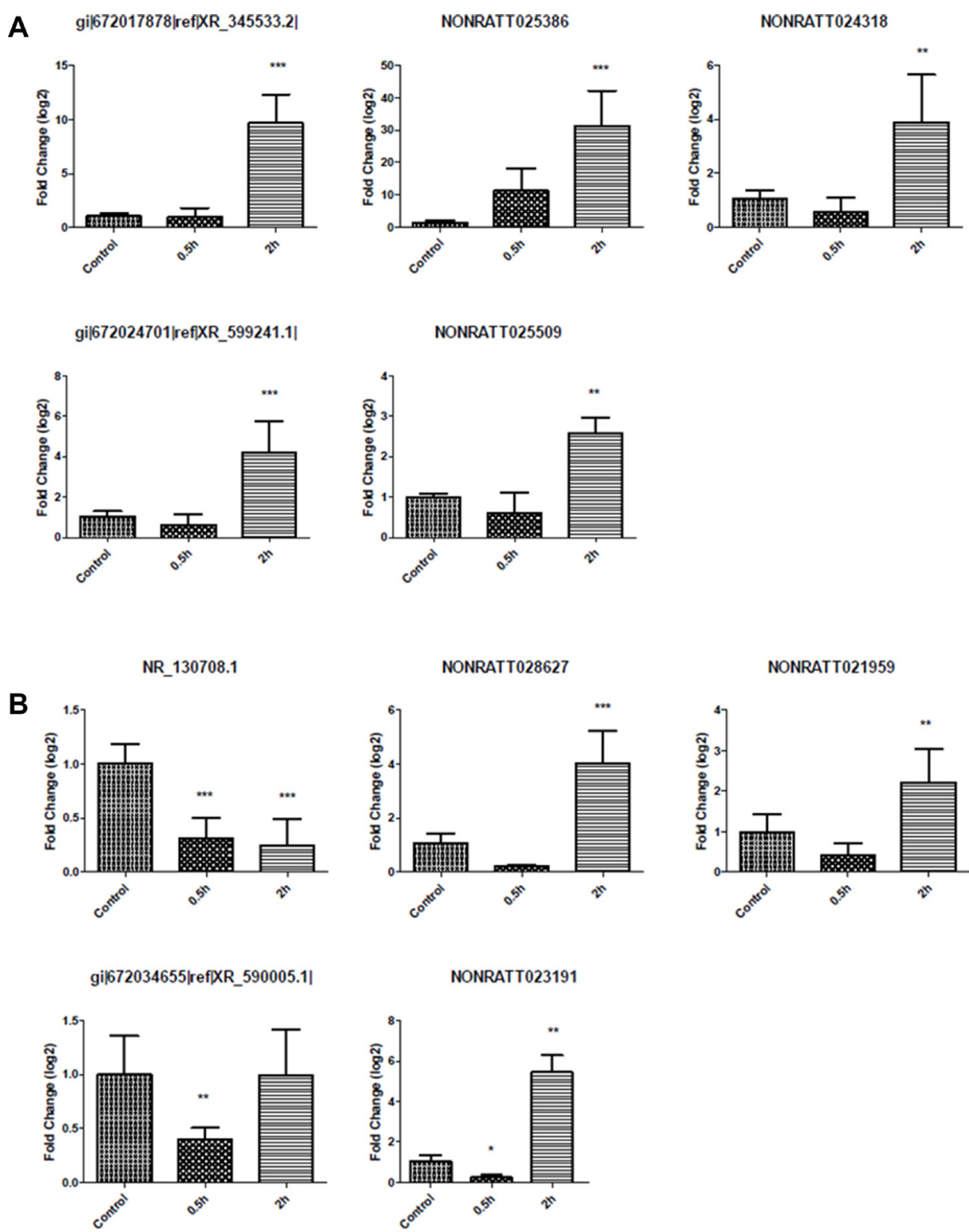

Figure 6: The expression of 10 IncRNA was analyzed in the myocardial tissues at different time points $(0.5 \mathrm{~h} / 2 \mathrm{~h})$ after cardiac ischemia-reperfusion injury. The expressions of lncRNA XR_345533.2, NONRATT025386, NONRATT024318, XR_599241.1, and NONRATT025509 were significantly up-regulated underlying both $0.5 \mathrm{~h}$ group and $2 \mathrm{~h}$ group. The expression of lncRNA NR_130708.1 was significantly down-regulated underlying both $0.5 \mathrm{~h}$ group and $2 \mathrm{~h}$ group. One-way ANOVA (Dunnelt: Compare all columns vs. naive column). ${ }^{*} P<0.05,{ }^{* *} P<0.01,{ }^{* * *} P<0.001$. 
Table 2: The detail information of the top 20 down-regulated IncRNAs in the ischemic region at $2 \mathrm{~h}$ after reperfusion

\begin{tabular}{lccc}
\hline Lnc RNAs (seqname) & fold change (R/N) & RNA length & Chromosome \\
\hline gi|672036855|ref|XR_590210.1| & -218.269 & 395 & 1 \\
NONRATT002188 & -49.5425 & 455 & 1 \\
gi|672034598|ref|XR_589980.1| & -45.2882 & 692 & 1 \\
gi|672012815|ref|XR_598701.1| & -44.1724 & 572 & 1 \\
gi|672036840|ref|XR_590197.1| & -42.3325 & 1597 & 1 \\
gi|672033468|ref|XR_589535.1| & -38.0944 & 910 & 1 \\
gi|672034607|ref|XR_589989.1| & -34.702 & 478 & 1 \\
NONRATT015339 & -33.0362 & 712 & 2 \\
gi|672016307|ref|XR_599988.1| & -32.6989 & 886 & 2 \\
NONRATT017954 & -32.2738 & 380 & 3 \\
NONRATT001682 & -29.1733 & 423 & 1 \\
NONRATT010246 & -27.7605 & 1384 & 1 \\
gi|672034371|ref|XR_589941.1| & -27.4956 & 322 & 1 \\
NONRATT000221 & -26.2891 & 564 & 1 \\
gi|672013705|ref|XR_598835.1| & -26.2395 & 965 & 1 \\
gi|672034596|ref|XR_589977.1| & -24.9653 & 711 & 1 \\
NONRATT002479 & -24.7847 & 1016 & 1 \\
NONRATT001101 & -23.8465 & 290 & 14 \\
gi|672076298|ref|XR_595802.1| & -23.594 & 1183 & 15 \\
NONRATT010626 & -23.3895 & 1394 & 1 \\
\hline
\end{tabular}

Values are fold changes (FC) in the reperfusion groups (reperfusion 2 h) over the control group (N $>2.0$-fold; $p<0.05$ by analysis of variance)
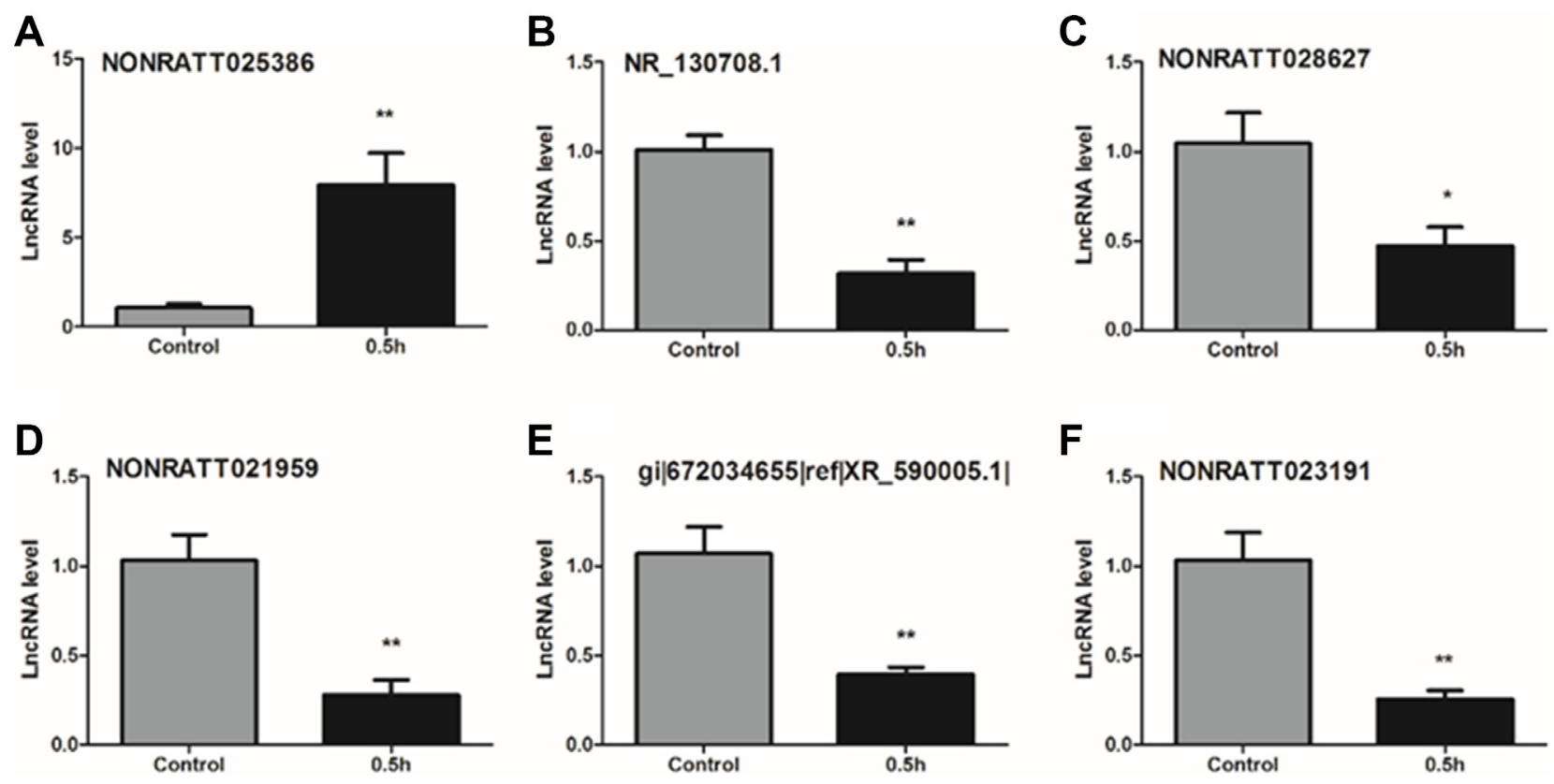

Figure 7: Real-time quantitative PCR (RT-qPCR) validation of 6 deregulated lncRNAs in the myocardium from MIRI rat model. The expressions of lncRNA NONRATT025386 (A) was significantly up-regulated underlying $0.5 \mathrm{~h}$ group. The expression of lncRNA NR_130708.1 (B), NONRATT028627 (C), NONRATT021959 (D), gi|672034655|ref|XR_590005.1| (E) and NONRATT023191 (F) were significantly down-regulated. Mann-Whitney test. ${ }^{*} P<0.05,{ }^{* *} P<0.01$. 
involved in posttranscriptional regulation with miRNAs [29]. In this study, we unveiled differential expression of many mRNAs and lncRNAs in the myocardial ischemic regions, further suggesting that these altered genes might be involved in the response to cardiac injury. Although the functions of these mRNA and lncRNAs are not fully known, our findings provide novel insights about the molecular mechanism of I/R-induced myocardial damage.

Among the differentially expressed mRNAs, ASIC3, P2X3R, TRPM8 and ACPP had been reported in the study of heart disease. van Duijnhoven et al reported that the development and characterization of radiolabeled matrix metalloproteinases (MMP)-2/9 sensitive activatable cell-penetrating peptide probes (ACPPs) to assess MMP activity in myocardial remodeling in vivo, and found that radiolabeled MMP sensitive ACPP probes enable to assess MMP activity in the course of remodeling postmyocardial infarction [30]. Düzen et al observed marked increases in TRPML1-3, TRPA1, transient receptor potential melastatin subtype (TRPM)1-8, TRPC1-7, TRPV1-6, and PKD2 (TRPP2) gene expressions in nonvalvular atrial fibrillation (NVAF) patients, whereas there was no change in PKD1 (TRPP1) gene expression, suggesting that elevated gene expressions of TRP channels may be associated with the pathogenesis of NVAF [31]. Xiong et al pointed that activation of TRPM8 attenuates cold-induced hypertension through ameliorating vascular mitochondrial dysfunction [32]. Zhang et al demonstrated that myocardial ischemic nociceptive signaling mediated by $\mathrm{P} 2 \mathrm{X} 3$ receptor in rat stellate ganglion neurons [33]. Pijacka et al showed the purinergic receptors in the carotid body as a new drug target for controlling hypertension

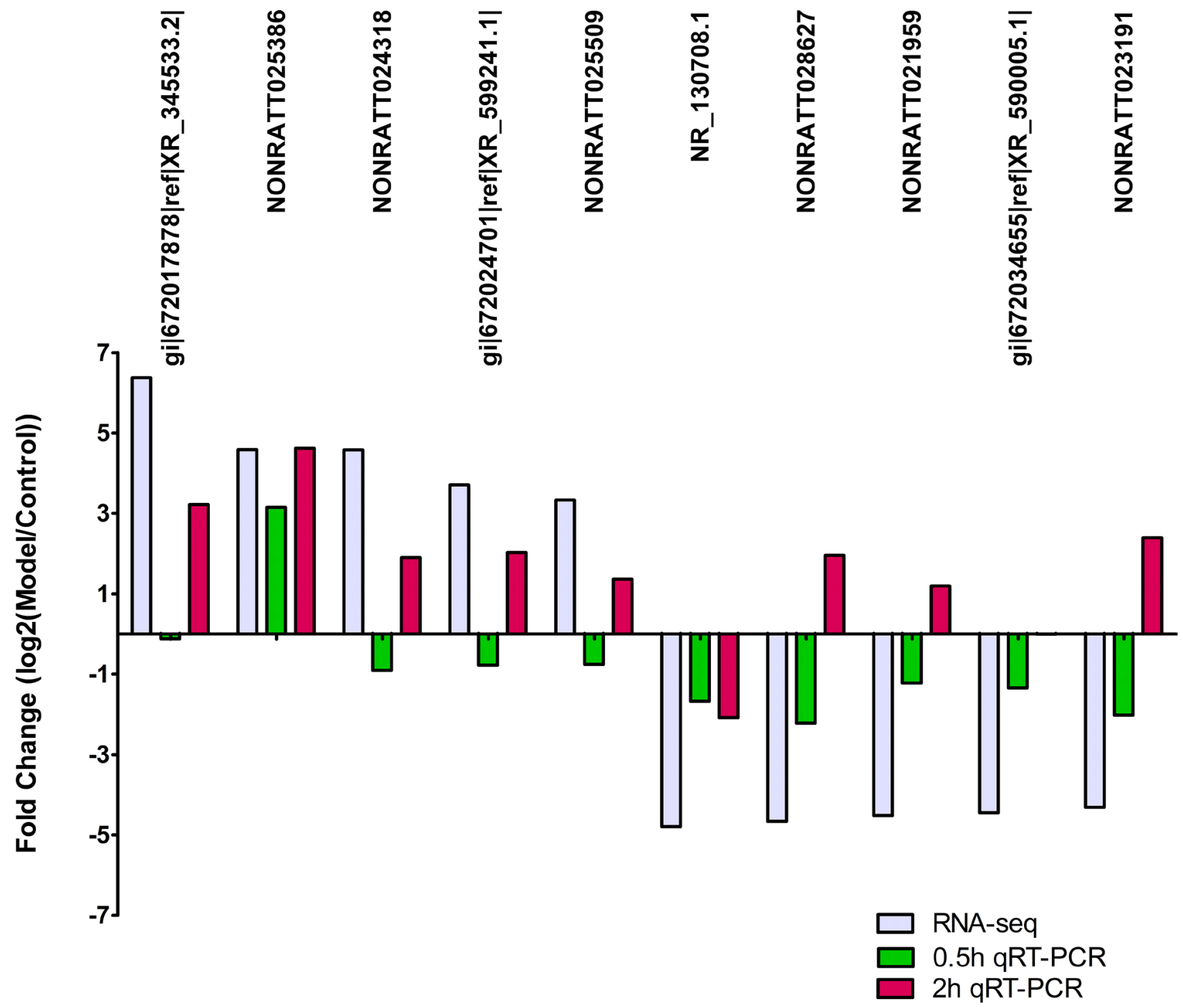

Figure 8: Validation of differential expression IncRNAs of the myocardial tissues at different time points $(0.5 \mathrm{~h} / 2 \mathrm{~h})$ after cardiac ischemia-reperfusion injury. Five up-regulated lncRNAs and five down-regulated lncRNAs were validated by qRTPCR. The levels of lncRNAs were normalized to GAPDH and expressed as fold of change compared to control group. 
Table 3: The detail information of the top 20 up-regulated mRNAs in the ischemic region $2 \mathrm{~h}$ after reperfusion

\begin{tabular}{lccc}
\hline m RNAs (seqname) & fold change (R/N) & GENE_SYMBOL & CHROMOSOMAL_LOCATION \\
\hline A_64_P140025 & 474.7933 & Tyrp1 & chr5:99536404-99536463 \\
A_43_P22979 & 182.9550 & Tyrp1 & chr5:99536772-99536831 \\
A_44_P304082 & 85.08903 & Kcnk18 & chr1:265764505-265764564 \\
A_42_P798447 & 75.89409 & LOC687797 & chr12:41820042-41820101 \\
A_44_P419710 & 75.37812 & Ppef1 & chrX:55426098-55426157 \\
A_64_P064833 & 68.06827 & Pirt & chr10:53633404-53633463 \\
A_64_P073143 & 65.44893 & Asic3 & chr4:6127828-6127769 \\
A_64_P018681 & 63.93424 & P2rx3 & chr3:68228104-68228045 \\
A_44_P556989 & 59.66698 & Ngfr & chr10:84263141-84263082 \\
A_44_P111865 & 58.96756 & Cyp2a3 & chr1:81948552-81950011 \\
A_44_P259796 & 58.00981 & Asic3 & chr4:6127227-6127168 \\
A_64_P159190 & 56.45496 & Mrgprx1 & chr1:97920951-97920892 \\
A_42_P502621 & 45.42639 & Avil & \\
A_64_P094230 & 43.46884 & Asb15 & chr4_random:386202-386261 \\
A_43_P10303 & 42.36214 & Ppp1r1c & chr3:62620827-62620886 \\
A_64_P041581 & 41.7290 & Trpm8 & chr9:87278375-87278434 \\
A_64_P090883 & 39.48497 & Mrgprb4 & chr1:97967660-97967601 \\
A_64_P004458 & 34.19669 & Acpp & chr8:109370477-109370418 \\
A_64_P165996 & 34.07631 & Chrna6 & chr16:69018847-69018901 \\
A_64_P000192 & 31.33567 & Mrgprx1 & chr1:97919998-97919939
\end{tabular}

Values are fold changes (FC) in the reperfusion groups (reperfusion $2 \mathrm{~h}$ ) over the control group (N $>2.0$-fold; $\mathrm{p}<0.05$ by analysis of variance)

$[34,35]$. Cheng et al indicated that acid-sensing ion channel 3, but not capsaicin receptor TRPV1, played a protective role in isoproterenol-induced myocardial ischemia in mice [36].

Further, we verified that gene expressions of the myocardial ischemic regions are varied in different time points after cardiac I/R injury by RT-qPCR validation. Our results indicated that the expressions of lncRNA XR_345533.2, NONRATT025386, NONRATT024318, XR_599241.1, and NONRATT025509 were significantly up-regulated in $2 \mathrm{~h}$ group compared with control group and $0.5 \mathrm{~h}$ group, whereas the expression of IncRNA NR_130708.1 was significantly down-regulated between $0.5 \mathrm{~h}$ group and $2 \mathrm{~h}$ group compared with control group, and had no statistically different between $0.5 \mathrm{~h}$ group and $2 \mathrm{~h}$ group. Otherwise, the expressions of IncRNA NONRATT028627, NONRATT021959, and NONRATT023191 were significantly up-regulated in $2 \mathrm{~h}$ group compared with control and $0.5 \mathrm{~h}$ groups, whereas the expressions of lncRNA gi|672034655|ref|XR_590005.1| was significantly down-regulated in $0.5 \mathrm{~h}$ group compared with control group, and had no statistically different between control group and $2 \mathrm{~h}$ group.

In summary, our data indicate that differential expression patterns of mRNAs and lncRNAs of the ischemic tissues in different time points after cardiac $I / R$ injury in rats, and suggest potential clinical applicability to identify effective biomarkers for the cardiac injury.

\section{MATERIALS AND METHODS}

\section{Animals and ethic statement}

Male adult Sprague-Dawley rats (SPF class, each weighing $250 \sim 300 \mathrm{~g}$ ) were obtained from the Tongji Laboratory Animal Center (No. 42000600011122), and were housed in cages in groups of three, maintained at $22-25^{\circ} \mathrm{C}$ with a natural light-dark cycle. The current study was performed in accordance with the directives outlined in the Guidelines for the Care and Use of Laboratory Animals (US National Institutes of Health). Animal care and experimental protocols were approved by the Committee on Animal Care of Tongji Medical University, Wuhan, Hubei, China (IRBID:TJA0804).

\section{Establishment of rat models with myocardial ischemia/reperfusion injury}

Myocardial I/R surgery were performed as previously described [6, 37-39]. Briefly, rats were 
Table 4: The detail information of the top 20 down-regulated mRNAs in the ischemic region $2 \mathrm{~h}$ after reperfusion

\begin{tabular}{|c|c|c|c|}
\hline m RNAs (seqname) & fold change $(\mathrm{R} / \mathrm{N})$ & GENE_SYMBOL & CHROMOSOMAL_LOCATION \\
\hline A_64_P244020 & -53.3920 & XM_006227951 & chrUn:42644932-42644873 \\
\hline A_64_P166479 & -53.2111 & XM_006227170 & chr1:52447851-52447910 \\
\hline A_64_P055634 & -52.9583 & & chrUn_random:003901566-003901625 \\
\hline A_64_P025366 & -52.7065 & & $\operatorname{chr} 1: 051379753-051379812$ \\
\hline A_64_P146443 & -39.8308 & & chr16:027206081-027206022 \\
\hline A_64_P221663 & -39.7231 & XM_003748704 & chr1:51977510-51977451 \\
\hline A_64_P043280 & -37.7585 & & chr16:027846591-027846532 \\
\hline A_64_P146268 & -34.3418 & & chr1:051278680-051278621 \\
\hline A_64_P021409 & -33.8364 & XM_003753181 & chr1:48965095-48965154 \\
\hline A_64_P019815 & -31.5077 & & chr1:049995024-049995083 \\
\hline A_64_P122161 & -30.8116 & XM_006254337 & $\operatorname{chr17:67813551-67813492}$ \\
\hline A_44_P974207 & -30.6207 & & chr1:051789811-051789870 \\
\hline A_64_P150351 & -30.4985 & & chrUn:019914712-019914653 \\
\hline A_64_P091294 & -30.3642 & & chr20:038380693-038380752 \\
\hline A_44_P185375 & -30.0411 & NM_001106764 & chr7:13894754-13894695 \\
\hline A_44_P135744 & -29.9762 & XM_006227354 & chrX:78955039-78955098 \\
\hline A_64_P155787 & -28.2512 & & chrUn:003105376-003105317 \\
\hline A_64_P028860 & -27.4549 & & chrUn:002037629-002037688 \\
\hline A_64_P139179 & -26.8976 & & chr1:050493160-050493219 \\
\hline A_64_P016196 & -26.7367 & & chrUn:049752903-049752844 \\
\hline
\end{tabular}

Values are fold changes $(\mathrm{FC})$ in the reperfusion groups (reperfusion $2 \mathrm{~h}$ ) over the control group (N $>2.0$-fold; $\mathrm{p}<0.05$ by analysis of variance)

anesthetized; a tracheal intubation was set up. Then an invasive incision was made to expose the heart at the fourth intercostal space. Then the left anterior descending coronary artery was located and ligatured until myocardial ischemia occurred which was indicated by visualizing a marked epicardial cyanosis. After $30 \mathrm{~min}$ of myocardial ischemia, the trap of the left anterior artery was opened. Reperfusion was allowed for $0.5 \mathrm{~h}$ or $2 \mathrm{~h}$.

\section{Experimental protocols}

Experiment A Animals were randomly divided into two groups: control group (Sham, $n=3$ ) and I/R group ( $30 \mathrm{~min}$ ischemia followed by $2 \mathrm{~h}$ reperfusion, $n=$ $3)$. The myocardial ischemic regions were prepared for LncRNA + mRNA Rat Gene Expression Microarray and Real-Time quantitative PCR (RT-qPCR).

Experiment B Rats were randomly assigned to three groups: (1) control group $(n=6)$; (2) 0.5 h group (30 min ischemia followed by $0.5 \mathrm{~h}$ reperfusion, $n=6$ ); (3) $2 \mathrm{~h}$ group ( $30 \mathrm{~min}$ ischemia followed by $2 \mathrm{~h}$ reperfusion, $n$
$=6$ ). The myocardial ischemic regions were prepared for RT-qPCR.

\section{Tissue preparation}

After $0.5 \mathrm{~h}$ or $2 \mathrm{~h}$ reperfusion, rats were immediately decapitated by cervical dislocation. Following decapitation, the myocardial ischemic regions were dissected during a dissection microscope and taken for subsequent analysis. The tissue was flash frozen in liquid nitrogen. Total RNA was isolated using Trizol ${ }^{\circledR}$ reagent (Invitrogen, Carlsbad CA). RNA samples were performed by Ambion mirVana miRNA Isolation Kit for purity and concentration.

\section{Gene expression microarray}

High quality samples containing $200 \mathrm{ng}$ of total RNA were used on LncRNA+mRNA Rat Gene Expression microarray (Agilent 8x60K chips) by Capitalbio Technology Corporation. Gene profiling of the myocardial ischemic regions from I/R group and control group were carried out according to the manufacturer's instructions [40-42]. 
Table 5: Primer sequences for RT-qPCR

\begin{tabular}{llll}
\hline Gene & Long & Forward $\left(5^{\prime}\right.$ to $\left.3^{\prime}\right)$ & Reverse $\left(5^{\prime}\right.$ to $\left.3^{\prime}\right)$ \\
\hline Up & & & \\
XR_345533.2 & 132 & GAAAGGTCACGAGGCAAAGG & TCAGCAGATGTCAGGCAAGAA \\
NONRATT025386 & 86 & GGGTCTGGGGTGGGCTAA & GGAGGTTTCTGAGTGGGATGTG \\
NONRATT024318 & 144 & AAAGGCTTCGTCGTCCAACA & TCTGCCGATAGTAAAAGACCAATA \\
XR_599241.1 & 88 & GTGCTCATCAACACGCATTCA & TTCTTAGGGTCTGCCTCCAAC \\
NONRATT025509 & 175 & CTCCAGCCCCTGTCCAAA & AGCCCCATCCTGAGCACC \\
Down & & & \\
NR_130708.1 & 225 & GAATCCTTCCGCTCTAAATCCC & TCTGCCTTGTTATCTTACCAGTCC \\
NONRATT028627 & 208 & GAACTGCTTTTCCCACCTGAT & GCCCCTTTTAGTGTCTTGCTT \\
NONRATT021959 & 206 & AAGAACCCTAAGAGCCCAGGAG & TGACGGAAAACAAGGCAAAGTA \\
XR_590005.1 & 238 & AGTCGGGTAGTTCTGGCTCTG & AATAGTCCCCTCATCAATCCTTT \\
NONRATT023191 & 144 & CCCAGCCTGTCGCTTTGA & TGACCCAGCACCCCACTT \\
GAPDH & & CGCTAACATCAAATGGGGTG & TTGCTGACAATCTTGAGGGAG \\
\hline RT-qPCR:
\end{tabular}

RT-qPCR: reverse transcriptase quantitative polymerase chain reaction

\section{Real-time quantitative PCR}

$2 \mu \mathrm{g}$ of total RNA was extracted from the myocardial ischemic regions responding to $\mathrm{I} / \mathrm{R}$ using TRIzol reagent (Invitrogen, USA) as described previously [43-47]. The threshold cycle (CT) was used to estimate the amount of target mRNA. The comparative CT method with the formula for relative fold-change $=2^{-\Delta \Delta C \mathrm{~T}}$ was used to quantify the amplified transcripts. The specific forward (F) and reverse (R) primer sequences (Table 5) were designed. Experiments were evaluated in triplicate.

\section{Microarray imaging data, Gene ontology and KEGG pathway analysis}

The $\operatorname{lncRNA}+$ mRNA array $\mathrm{v} 4.0$ data were analyzed by using the Agilent GeneSpring software V13.0. The differentially expressed genes from the myocardial ischemic regions were selected by using the threshold values of $\geq 2$ or $\leq-2$-fold change, and the tree visualization from the myocardial ischemic regions was performed by using Java Treeview (Stanford University School of Medicine, Stanford, CA, USA) [48, 49]. The lncRNA/mRNA expression profiles from the myocardial ischemic regions between $\mathrm{I} / \mathrm{R}$ group and control group were screened by volcano plot filtering. The differential lncRNA/mRNA expression from the myocardial ischemic regions was determined with Gene Ontology program. The key regulatory pathways in the myocardial ischemic regions responding to $\mathrm{I} / \mathrm{R}$ were analyzed using the KEGG pathway analysis.

\section{Statistics analysis}

All quantification data are presented as mean \pm SEM, and error bars represent SEM. To test for differences between the two groups, Mann-Whitney test were applied for each differentially expressed gene. The statistical analyses were done using $t$ test, and $P<0.05$ was considered statistically significant.

\section{CONFLICTS OF INTEREST}

The authors have no conflicts of interest related to this paper.

\section{FUNDING}

This work was supported by grants from National Natural Science Foundation of P.R. China (No. 81670240 to H.B. X, 81770283 to M.H. F), National Natural Science Foundation of Hubei Province (No. 2016CFB625 to H.B. X), Research project of Chinese Medicine Bureau in Guangdong Province (No. 20172067 to Q. L), and Medical innovation project in Fujian Province (No. 2017-CX-48 to S.Y. L).

\section{REFERENCES}

1. Timotin A, Pisarenko O, Sidorova M, Studneva I, Shulzhenko V, Palkeeva M, Serebryakova L, Molokoedov A, Veselova O, Cinato M, Tronchere H, Boal F, Kunduzova O. Myocardial protection from ischemia/reperfusion injury by exogenous galanin fragment. Oncotarget. 2017; 8:21241-21252. https://doi.org/10.18632/oncotarget.15071.

2. Xu AJ, Song ZP, Peng YW, Xiang HB. Change of mitochondrial function in the early stage after cardiac ischemia-reperfusion injury in mice. Int J Clin Exp Med. 2016; 9:2549-2554.

3. De Hert S, Moerman A. Myocardial injury and protection related to cardiopulmonary bypass. Best practice \& research. 2015; 29:137-149. 
4. Murphy E, Steenbergen C. Mechanisms underlying acute protection from cardiac ischemia-reperfusion injury. Physiol Rev. 2008; 88:581-609.

5. Cave A, Garlick P. Preconditioning with ischemia: a delay of lethal cell injury in ischemic myocardium. Journal of molecular and cellular cardiology. 2000; 32:1759-1760.

6. Murry CE, Jennings RB, Reimer KA. Preconditioning with ischemia: a delay of lethal cell injury in ischemic myocardium. Circulation. 1986; 74:1124-1136.

7. Pichot S, Mewton N, Bejan-Angoulvant T, Roubille F, Rioufol G, Giraud C, Boussaha I, Lairez O, Elbaz M, Piot C, Angoulvant D, Ovize M. Influence of cardiovascular risk factors on infarct size and interaction with mechanical ischaemic postconditioning in ST-elevation myocardial infarction. Open heart. 2015; 2:e000175.

8. Nazarenko GI, Skvortsova VI, Kleĭmenova EB, Konstantinova MV. [The role of genetic predisposition in the development of cardiovascular diseases (myocardial infarction, ischemic stroke, unstable stenocardia) and its interaction with conventional risk factors]. [Article in Russian]. Zh Nevrol Psikhiatr Im S S Korsakova. 2009 (Suppl 2); 109:19-25.

9. Ferdinandy P, Schulz R, Baxter GF. Interaction of cardiovascular risk factors with myocardial ischemia/ reperfusion injury, preconditioning, and postconditioning. Pharmacological reviews. 2007; 59:418-458.

10. Doggen CJ, Cats VM, Bertina RM, Rosendaal FR. Interaction of coagulation defects and cardiovascular risk factors: increased risk of myocardial infarction associated with factor V Leiden or prothrombin 20210A. Circulation. 1998; 97:1037-1041.

11. Aleshin A, Sawa Y, Ono M, Funatsu T, Miyagawa S, Matsuda H. Myocardial protective effect of FR167653; a novel cytokine inhibitor in ischemic-reperfused rat heart. European journal of cardio-thoracic surgery. 2004; 26:974980.

12. Yu P, Zhang J, Yu S, Luo Z, Hua F, Yuan L, Zhou Z, Liu Q, Du X, Chen S, Zhang L, Xu G. Protective Effect of Sevoflurane Postconditioning against Cardiac Ischemia/ Reperfusion Injury via Ameliorating Mitochondrial Impairment, Oxidative Stress and Rescuing Autophagic Clearance. PLoS One. 2015; 10:e0134666.

13. Han Y, Zhao H, Tang H, Li X, Tan J, Zeng Q, Sun C. 20-Hydroxyeicosatetraenoic acid mediates isolated heart ischemia/reperfusion injury by increasing NADPH oxidasederived reactive oxygen species production. Circulation journal. 2013; 77:1807-1816.

14. Qiao S, Xie H, Wang C, Wu X, Liu H, Liu C. Delayed anesthetic preconditioning protects against myocardial infarction via activation of nuclear factor-kappaB and upregulation of autophagy. Journal of anesthesia. 2013; 27:251-260

15. Liu QQ, Liu H, He ZG, Zhang SJ, Liu BW, Wang L, Qiu WH, Xu Q, Xiang HB, Lv YM. Differential gene and lncRNA expression in the lower thoracic spinal cord following ischemia/reperfusion-induced acute kidney injury in rats. Oncotarget. 2017; 8:53465-53481. https://doi. org/10.18632/oncotarget.18584.

16. Liu BW, Li ZX, He ZG, Liu C, Xiong J, Xiang HB. Altered expression of target genes of spinal cord in different itch models compared with capsaicin assessed by RT-qPCR validation. Oncotarget. 2017; 8:74423-74433. https://doi. org/10.18632/oncotarget.20148.

17. Wang S, Xu H, Zou L, Xie J, Wu H, Wu B, Yi Z, Lv Q, Zhang X, Ying M, Liu S, Li G, Gao Y, et al. LncRNA uc.48+ is involved in diabetic neuropathic pain mediated by the $\mathrm{P} 2 \mathrm{X}$ receptor in the dorsal root ganglia. Purinergic signalling. 2016; 12:139-148.

18. Boon RA, Jae N, Holdt L, Dimmeler S. Long Noncoding RNAs: From Clinical Genetics to Therapeutic Targets? J Am Coll Cardiol. 2016; 67:1214-1226.

19. Zhao X, Tang Z, Zhang H, Atianjoh FE, Zhao JY, Liang L, Wang W, Guan X, Kao SC, Tiwari V, Gao YJ, Hoffman $\mathrm{PN}$, Cui $\mathrm{H}$, et al. A long noncoding RNA contributes to neuropathic pain by silencing Kcna2 in primary afferent neurons. Nat Neurosci. 2013; 16:1024-1031.

20. Wang Q, Li ZX, Liu BW, He ZG, Liu C, Chen M, Liu SG, Wu WZ, Xiang HB. Altered expression of differential gene and lncRNA in the lower thoracic spinal cord on different time courses of experimental obstructive jaundice model accompanied with altered peripheral nociception in rats. Oncotarget. 2017; 8:106098-106112.

21. Vausort M, Wagner DR, Devaux Y. Long noncoding RNAs in patients with acute myocardial infarction. Circulation research. 2014; 115:668-677.

22. Grote P, Wittler L, Hendrix D, Koch F, Wahrisch S, Beisaw A, Macura K, Blass G, Kellis M, Werber M, Herrmann BG. The tissue-specific lncRNA Fendrr is an essential regulator of heart and body wall development in the mouse. Developmental cell. 2013; 24:206-214.

23. Klattenhoff CA, Scheuermann JC, Surface LE, Bradley RK, Fields PA, Steinhauser ML, Ding H, Butty VL, Torrey L, Haas S, Abo R, Tabebordbar M, Lee RT, et al. Braveheart, a long noncoding RNA required for cardiovascular lineage commitment. Cell. 2013; 152:570-583.

24. Bar C, Chatterjee S, Thum T. Long Noncoding RNAs in Cardiovascular Pathology, Diagnosis, and Therapy. Circulation. 2016; 134:1484-1499.

25. Ye Y, Perez-Polo JR, Qian J, Birnbaum Y. The role of microRNA in modulating myocardial ischemia-reperfusion injury. Physiological genomics. 2011; 43:534-542.

26. Wang K, Liu F, Zhou LY, Ding SL, Long B, Liu CY, Sun T, Fan YY, Sun L, Li PF. miR-874 regulates myocardial necrosis by targeting caspase- 8 . Cell death \& disease. 2013; 4:e709.

27. Yang Q, Yang K, Li A. microRNA-21 protects against ischemia-reperfusion and hypoxia-reperfusion-induced cardiocyte apoptosis via the phosphatase and tensin 
homolog/Akt-dependent mechanism. Molecular medicine reports. 2014; 9:2213-2220.

28. Wu Z, Qi Y, Guo Z, Li P, Zhou D. miR-613 suppresses ischemia-reperfusion-induced cardiomyocyte apoptosis by targeting the programmed cell death 10 gene. Bioscience trends. 2016; 10:251-257.

29. Diaz I, Calderon-Sanchez E, Toro RD, Avila-Medina J, de Rojas-de Pedro ES, Dominguez-Rodriguez A, Rosado JA, Hmadcha A, Ordonez A, Smani T. miR-125a, miR-139 and miR-324 contribute to Urocortin protection against myocardial ischemia-reperfusion injury. Scientific reports. 2017; 7:8898.

30. van Duijnhoven SM, Robillard MS, Hermann S, Kuhlmann MT, Schafers M, Nicolay K, Grull H. Imaging of MMP activity in postischemic cardiac remodeling using radiolabeled MMP-2/9 activatable peptide probes. Molecular pharmaceutics. 2014; 11:1415-1423.

31. Duzen IV, Yavuz F, Vuruskan E, Saracoglu E, Poyraz F, Goksuluk H, Candemir B, Demiryurek S. Leukocyte TRP channel gene expressions in patients with non-valvular atrial fibrillation. Scientific reports. 2017; 7:9272.

32. Xiong S, Wang B, Lin S, Zhang H, Li Y, Wei X, Cui Y, Lu Z, Gao P, Li L, Zhao Z, Liu D, Zhu Z. Activation of Transient Receptor Potential Melastatin Subtype 8 Attenuates ColdInduced Hypertension Through Ameliorating Vascular Mitochondrial Dysfunction. Journal of the American Heart Association. 2017; 6. pii: e005495. https://doi.org/10.1161/ JAHA.117.005495.

33. Zhang C, Li G, Liang S, Xu C, Zhu G, Wang Y, Zhang A, Wan F. Myocardial ischemic nociceptive signaling mediated by $\mathrm{P} 2 \mathrm{X} 3$ receptor in rat stellate ganglion neurons. Brain Res Bull. 2008; 75:77-82.

34. Pijacka W, Moraes DJ, Ratcliffe LE, Nightingale AK, Hart EC, da Silva MP, Machado BH, McBryde FD, Abdala AP, Ford AP, Paton JF. Purinergic receptors in the carotid body as a new drug target for controlling hypertension. Nat Med. 2016; 22:1151-1159.

35. McBryde FD, Abdala AP, Hendy EB, Pijacka W, Marvar P, Moraes DJ, Sobotka PA, Paton JF. The carotid body as a putative therapeutic target for the treatment of neurogenic hypertension. Nat Commun. 2013; 4:2395.

36. Cheng CF, Chen IL, Cheng MH, Lian WS, Lin CC, Kuo TB, Chen CC. Acid-sensing ion channel 3, but not capsaicin receptor TRPV1, plays a protective role in isoproterenolinduced myocardial ischemia in mice. Circulation journal. 2011; 75:174-178.

37. Huang $\mathrm{CH}$, Lai CC, Yang AH, Chiang SC. Myocardial preconditioning reduces kidney injury and apoptosis induced by myocardial ischaemia and reperfusion. European journal of cardio-thoracic surgery. 2015; 48:382-391.

38. Borst O, Ochmann C, Schonberger T, Jacoby C, Stellos K, Seizer P, Flogel U, Lang F, Gawaz M. Methods employed for induction and analysis of experimental myocardial infarction in mice. Cellular physiology and biochemistry. 2011; 28:1-12.
39. Pisarenko OI, Shulzhenko VS, Studneva IM, Serebryakova LI, Pelogeykina YA, Veselova OM. Signaling pathways of a structural analogue of apelin-12 involved in myocardial protection against ischemia/reperfusion injury. Peptides. 2015; 73:67-76.

40. Orom UA, Derrien T, Beringer M, Gumireddy K, Gardini A, Bussotti G, Lai F, Zytnicki M, Notredame C, Huang Q, Guigo $\mathrm{R}$, Shiekhattar R. Long noncoding RNAs with enhancer-like function in human cells. Cell. 2010; 143:46-58.

41. Patterson TA, Lobenhofer EK, Fulmer-Smentek SB, Collins PJ, Chu TM, Bao W, Fang H, Kawasaki ES, Hager J, Tikhonova IR, Walker SJ, Zhang L, Hurban P, et al. Performance comparison of one-color and two-color platforms within the MicroArray Quality Control (MAQC) project. Nature biotechnology. 2006; 24:1140-1150.

42. Bottomly D, Walter NA, Hunter JE, Darakjian P, Kawane S, Buck KJ, Searles RP, Mooney M, McWeeney SK, Hitzemann R. Evaluating gene expression in C57BL/6J and DBA/2J mouse striatum using RNA-Seq and microarrays. PLoS One. 2011; 6:e17820.

43. Ke C, Gao F, Tian X, Li C, Shi D, He W, Tian Y. Slit2/ Robo1 Mediation of Synaptic Plasticity Contributes to Bone Cancer Pain. Mol Neurobiol. 2017; 54:295-307.

44. Guan XH, Fu QC, Shi D, Bu HL, Song ZP, Xiong BR, Shu B, Xiang HB, Xu B, Manyande A, Cao F, Tian YK. Activation of spinal chemokine receptor CXCR3 mediates bone cancer pain through an Akt-ERK crosstalk pathway in rats. Exp Neurol. 2015; 263:39-49.

45. Bu H, Shu B, Gao F, Liu C, Guan X, Ke C, Cao F, Hinton AO Jr, Xiang H, Yang H, Tian X, Tian Y. Spinal IFNgamma-induced protein-10 (CXCL10) mediates metastatic breast cancer-induced bone pain by activation of microglia in rat models. Breast Cancer Res Treat. 2014; 143:255-263.

46. Xu B, Guan XH, Yu JX, Lv J, Zhang HX, Fu QC, Xiang HB, Bu HL, Shi D, Shu B, Qin LS, Manyande A, Tian YK. Activation of spinal phosphatidylinositol 3-kinase/protein kinase B mediates pain behavior induced by plantar incision in mice. Exp Neurol. 2014; 255:71-82.

47. Fu Q, Shi D, Zhou Y, Zheng H, Xiang H, Tian X, Gao F, Manyande A, Cao F, Tian Y, Ye D. MHC-I promotes apoptosis of GABAergic interneurons in the spinal dorsal horn and contributes to cancer induced bone pain. Exp Neurol. 2016; 286:12-20.

48. Barabasi AL, Oltvai ZN. Network biology: understanding the cell's functional organization. Nature reviews Genetics. 2004; 5:101-113.

49. Jia H, Osak M, Bogu GK, Stanton LW, Johnson R, Lipovich L. Genome-wide computational identification and manual annotation of human long noncoding RNA genes. RNA. 2010; 16:1478-1487. 